\title{
TIMELESS: A link between fly's circadian and photoperiodic clocks?
}

\author{
JAROSLAV PAVELKA ${ }^{1,2^{*}}$, KIMIO SHIMADA ${ }^{1}$ and VLADIMIR KOSTAL ${ }^{2}$ \\ ${ }^{1}$ Institute of Low Temperature Science, Hokkaido University, Sapporo, Japan \\ ${ }^{2}$ Institute of Entomology, Academy of Sciences, Branišovská 31, CZ-370 05 České Budějovice, Czech Republic
}

Key words. Insect, Chymomyza costata, diapause, circadian clocks, photoperiodism, time measurement, period, timeless

\begin{abstract}
Potential involvement of circadian clock genes in so far unknown mechanism of photoperiodic time measurement is an important question of insect life-cycle regulation science. Here we report about the cloning of full-length cDNA of the structural homologue of the Drosophila's timeless gene in Chymomyza costata. Its expression was compared in two strains: a wild-type strain, responding to short days by entering larval diapause and a npd-mutant strain, showing no photoperiodic response. The timeless mRNA transcripts were not detectable by Northern blot analysis in the fly heads of npd-mutants, while they were detectable and showed typical daily oscillations in the wild-type strain. After disrupting the normal process of timeless transcription in the wild-type strain by injection of timeless double-strandRNA into early embryos of wild-type (RNAi method: Kennerdell \& Carthew 1998, 2000), a certain proportion of the individuals adopted a $n p d$-mutant phenotype, showing no-diapause in response to short-daylength. Cloning of genomic DNA fragments revealed that $n p d$-mutants carry a different allele, timeless $s^{\text {ppd }}$, with a 13-bp insertion in an intron positioned within the 5'-leader sequence. Genetic linkage analysis showed that the 13-bp insertion (a marker for timeless ${ }^{n p d}$ ) and the absence of response to short days (a marker for $n p d$-phenotype) are strictly co-inherited in the F2 progeny of the reciprocal crosses between wild-type and $n p d$-mutant flies. Such results indicated that the locus $n p d$ could code for the timeless gene in C. costata and its product might thus represent a molecular link between circadian and photoperiodic clock systems in this fly.
\end{abstract}

\section{INTRODUCTION}

Circadian clock systems allow organisms to anticipate daily changes in environmental factors and appropriately tune their physiological state. Within the past three decades, starting with identification of the period gene locus in Drosophila melanogaster (Konopka \& Benzer, 1971), enormous progress has been made in describing the molecular details of circadian clocks in cyanobacteria, fungi, plants, insects and mammals (for review see: Dunlap, 1999; Harmer et al., 2001).

The photoperiodic time measurement system (photoperiodic clock) perceives seasonal change of day-length or night-length (for recent reviews on photoperiodism in different organisms see: Samach \& Coupland, 2000; Goldman, 2001; Roenneberg \& Merrow, 2001; Suzuki \& Johnson, 2001; Wehr, 2001), which signals for seasonally cycling deterioration of conditions for life/development and allows organisms to prepare in advance, by entering diapause state in insects, for example (Denlinger, 2000, 2002; Saunders, 2002). Physiological mechanisms of the photoperiodic time measurement system remain obscure. Part of the scientific community accepts that certain elements with circadian oscillatory nature may be functionally involved in photoperiodic clocks. This hypothesis, formulated first by Bünning (1936) for plants, has later received support from other organisms including insects (Saunders, 2002). Nevertheless, the evidence so far gathered is not conclusive enough (Tauber \& Kyriacou, 2001; Veerman, 2001).

A central question in the study of physiological basis of photoperiodism is whether the known molecular elements of circadian clocks may serve as functional parts of photoperiodic clock system. In insects, Saunders et al. (1989) analyzed photoperiodic response (diapause induction) in D. melanogaster carrying different mutant alleles of the period locus. They found that a double deletion of the period gene failed to prevent the ability of female flies to discriminate between long and short days. However, genetic dissection of geographical variation in diapause and eclosion rhythmicity in a closely related fly, $D$. littoralis, implied that the same central clock may be used for photoperiodic and circadian time measurements (Lankinen, 1986). More recently, Goto \& Denlinger (2002) reported that the amplitude and phase of period and timeless expression is affected by photoperiod in Sarcophaga crassipalpis fly heads. Experiments with mammals showed that some of the elements of central circadian clock (mPer, tau) might directly participate in decoding photoperiodic time (Loudon et al., 1998; Majercak et al., 1999; Messager et al., 1999; NuessleinHindelsheim et al., 2000; Sumová et al., 2002).

In the light of above information, we started an effort to elucidate the potential role of circadian clock genes in photoperiodism of the fly, Chymomyza costata (Diptera: Drosophilidae). The mature larvae of the wild-type (Sapporo) strain of the fly enter diapause in response to subcritically short days or low temperature (Riihimaa \& Kimura, 1989; Kostal et al., 2000a). In 1983, Riihimaa \& Kimura (1988) succeeded in selecting a mutant strain of flies which did not respond to a photoperiodic signal but were able to enter diapause at $11^{\circ} \mathrm{C}$; the authors named the strain as NPD (Non-Photoperiodic-Diapause). Later,

* Corresponding author. E-mail: pavelka@entu.cas.cz 


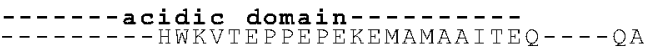

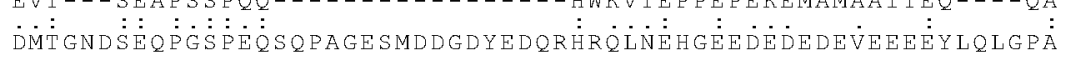
SMIMQLTQ-PADNAKTTTNTTCTANQ----EREKQPPPLPVRPLTCTQAERLGEMADET

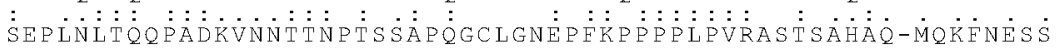
YPKHVSAVKRGQKSPHSGQLHLTRGRCFPQKRECASSQSELSDCGYGTQVENQESISTSS YASHVSAVKLGQKSPHAGQLQLTKGKCCPQKRECPSSQSELSDCGYGTQVENQESISTSS

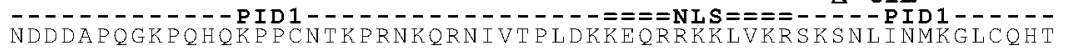

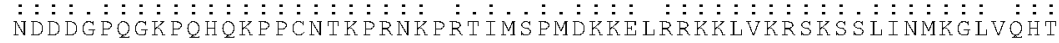
PTDDDISNLLKEFTVDFLLKGYNYLVKVLHLHITSNAKVS I T SHFFWLVAYFLKFAAQL

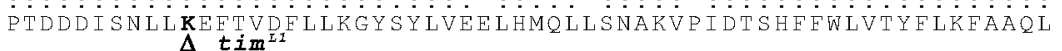
ELDMEHIDTILNFDVLTYLTSEGVSLCEQLELNARQEGSDLRPYLRRMHLVVTAIREFLQ

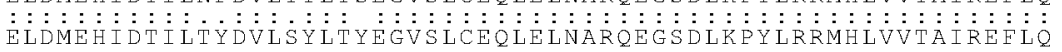
AIETYSKVTHLSEDDRTQLLKPQIQISAATDLRSLFVLLLRRFNPSIHSKQYLQDLVVTN

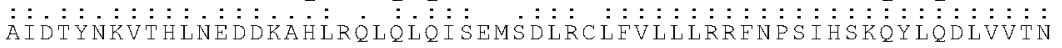
HKLMLVLDRAARLEGGQSVYLTEHLLOFATPEVMHYYGILLEDFNYNGEFLNDCIFTMMH

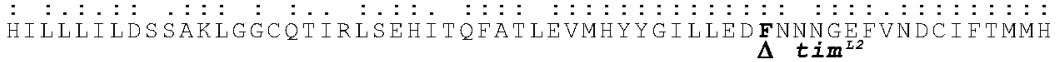
HIGGDLRQIGLFQPIILKTESRLWETDELCDDWTLIAYVIRKIMSTHPVS-VDLRTS

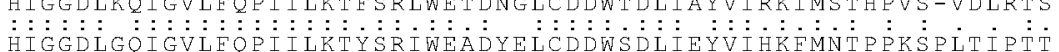

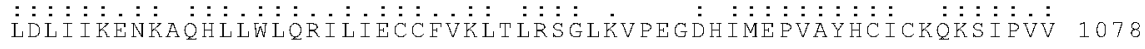

QWNNDQSAIMLYQPFVLLLHKLGIQLPADAGTIFAR IPDYWTPETMYGVAKKLGTLDKLT 1078

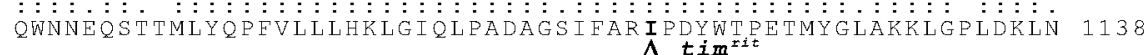
LRFDPIELEVASSTTPR--HCMKSLNSLSSVSSLDVDMPELEELPLIPEVDAAIERAH-- 1134

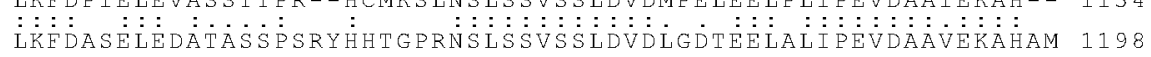
------EIFVAPKAKIVIQLERYYAGCYTSVPNWLQLVMRSKCIQQSVPSRPATDISDC 1187 ASTPSPSEITA TGA----DDESMHSSSQRAPTQRLLATSNSSNVNHATTLGCQ--PSIIGAHNDNSSSG 1240

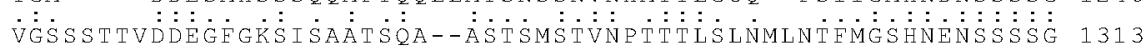
CGGTDSSQSMAAVVATRTTGNATPRKTAEAISRKTHMYEDAAMKS-FQRLQATNSHFS 1299 宅GG RANNLQQYSALVASIYENEMA-NCDNISMADLEHMYVSDEEDTHENHEQRVPYY 1355 RANULDE 
the rhythmicity of adult eclosion was studied and genetic dissection experiments confirmed that the nonphotoperiodism and eclosion arrhythmicity in the NPD strain were caused by mutation in a single autosomal gene locus npd (Riihimaa \& Kimura, 1989; Riihimaa, 1996; Lankinen \& Riihimaa, 1992, 1997). Formal analysis of the photoperiodic clock's function in C. costata revealed that an element with a circadian-oscillatory nature participates in photoperiodic time measurement (Yoshida \& Kimura, 1995; Kostal et al., 2000b). Shimada (1999) sequenced the per homologue in C. costata and found that the NPD flies have a 6-bp deletion site (deleting two amino acids) in the coding region, in addition to a few other point mutations (see accessions Nos. AB014476 and AB014477 in DDBJ/EMBL/GenBank database). These mutations were found to be primarily neither responsible for the loss of the eclosion rhythm nor for the loss of photoperiodic response in NPD strain. Nevertheless, the daily and circadian oscillations of the per gene mRNA abundance, that were detected in the Sapporo strain, were lost in the NPD strain, which suggested an impaired function of the central circadian clocks in $n p d-$ mutants (Kostal \& Shimada, 2001). The gene timeless codes for a protein (TIM), which forms a heterodimer with PER within the cytoplasm of Drosophila clock neurons; together they translocate to the nucleus where they repress their own transcription with the help of two dimerizing transcription factors, CYCLE and CLOCK, binding to E-box sequences in the period and timeless promoters. Such a negative feedback loop forms the core of the central circadian clock in Drosophila (Sehgal et al., 1994; Allada et al., 1998; Darlington et al., 1998; Rutilla et al., 1998).

Here we report an introductory analysis of the structure and expression of the gene timeless in two strains of $C$. costata (Sapporo and NPD). We found that the mRNA transcripts of C. costata's structural homologue of Drosophila's timeless gene are not detectable by Northern blot analysis in the NPD strain fly heads, while they are detectable and show typical daily oscillation in the Sapporo strain. After disrupting the normal process of timeless transcription in the Sapporo strain by the mean of RNA interference methodology (RNAi, Kennerdell \& Carthew 1998, 2000), a certain proportion of the individuals that were treated with timeless dsRNA adopted a npd-mutant phenotype, showing no-diapause in response to short daylength. Comparing the sequences of the genomic DNA fragment between the two strains revealed that the $n p d$-mutants carry a different allele, timeless ${ }^{n p d}$, with numerous point substitutions and a 13-bp insertion in an intron positioned within the 5'-leader sequence of the mRNA. Genetic linkage analysis showed that the 13-bp insertion (a marker for timeless ${ }^{\text {npd }}$ ) and the absence of response to short days (a marker for $n p d$-phenotype) are strictly co-inherited in the F2 progeny of the reciprocal crosses between Sapporo and NPD flies. Such results indicate that the gene timeless might play a direct role in photoperiodic induction of diapause in C. costata and its product might thus represent a molecular link between the circadian and photoperiodic clock systems.

\section{MATERIALS AND METHODS}

\section{Insects}

Two strains of Chymomyza costata were used for experiments: a wild-type (Sapporo) strain originally collected in Sapporo $\left(43^{\circ} \mathrm{N}\right)$, Japan in 1983 ; a non-photoperiodic-diapause $(n p d)$-mutant strain (NPD) which was isolated by Riihimaa \& Kimura (1988) from wild-type flies collected in Tomakomai $\left(42.3^{\circ} \mathrm{N}\right)$, Japan. Larvae, pupae and adults were cultured on an artificial diet of Lakovaara (1969) under a constant temperature of $18^{\circ} \mathrm{C}$ and a short-day (SD) photoperiod (10h light : 14h darkness) that induces larval diapause in $100 \%$ of the population of Sapporo strain but no-diapause in the NPD strain.

\section{DNA, RNA extractions}

Genomic DNA was extracted by homogenization of whole adults in DNAzol Reagent (GibcoBRL) using the manufacturer's instructions. Precipitated DNA was dissolved in water.

For total RNA extraction, adults were frozen on a metal block submerged in liquid nitrogen. Their heads were separated, RNA extracted by homogenization in ISOGEN (Nippon Gene, Japan) using the manufacturer's instructions, and dissolved in DEPCtreated water. Traces of DNA in total RNA samples were digested with DNase I (Roche), purified total RNA was isolated using standard phenol/chloroform extraction and re-dissolved in DEPC-treated water. Total RNA was extracted also from whole white puparia (freshly pupariated larvae, before formation of pupa), either from non-injected controls or from the "positive" individuals injected with timeless dsRNA in the RNAi experiment (see below)

Cloning of timeless and $\beta$-tubulin homologues, preparation of probes for Northern blot analysis

The timeless and $\beta$-tubulin cDNA fragments were obtained using the standard RT-PCR method. In the first step, cDNA synthesis was performed with ThermoScript RT-PCR System (GibcoBRL) according to the manufacturer's instructions. Total RNA (2mg) was primed with $2.5 \mu \mathrm{M}$ oligo $(\mathrm{dT})_{20}$ and reverse transcribed using $15 \mathrm{U}$ of the ThermoScript enzyme in $20 \mu 1$ reaction mixture. In the second step, aliquots of cDNA $(0.5 \mu)$ were amplified by a standard PCR with $2.5 \mathrm{U}$ Taq DNA polymerase (Takara, Japan) in $50 \mu \mathrm{l}$ reaction mixture $(10 \mathrm{mM}$ Tris- $\mathrm{HCl}, 50 \mathrm{mM} \mathrm{KCl}, 1.5 \mathrm{mM} \mathrm{MgCl} 2,0.8 \mathrm{mM}$ dNTP, $\mathrm{pH} 8.3$ ) under the following thermal conditions: $95^{\circ} \mathrm{C}, 3 \mathrm{~min} ; 30$ cycles of $94^{\circ} \mathrm{C}, 30 \mathrm{sec} ; 55^{\circ} \mathrm{C}, 30 \mathrm{sec} ; 72^{\circ} \mathrm{C}, 2 \mathrm{~min}$. The annealing temperature was changed between 50 and $65^{\circ} \mathrm{C}$ depending on $\mathrm{T}_{\mathrm{m}}$ values of primers. The time at $72^{\circ} \mathrm{C}$ was extended to 3 or $5 \mathrm{~min}$ depending on the length of target cDNA. PCR primers tim11, tim12 and tub1, tub2 (Table 1) were designed on the basis of published timeless and tubulin cDNA sequences from other drosophilid species. The PCR products were digested with EcoR I or Sau3A I restriction enzymes, and cloned into pBluescript SK $(+)$ vectors (Stratagene).

Fig. 1. Alignment of TIMELESS amino acid sequences from Chymomyza costata (C.cos) (EMBL/GeneBank/DDBJ accession number, AB073724) and Drosophila melanogaster (D.mel) (Swiss-Prot accession number, P49021) (alignment was performed using FASTA software; http://www.genome.ad.jp). Several known functional motifs are shown using dashed line above the sequence and the sites to which the $\mathrm{tim}^{S L}, \mathrm{tim}^{L 1}, \mathrm{tim}^{L 2}$ and $t \mathrm{tim} \mathrm{m}^{\text {rit }}$ mutations have been mapped are indicated by triangles (see text for explanations). Identical and positive amino acids are indicated by double dot (:) and single dot (.) marks, respectively. 


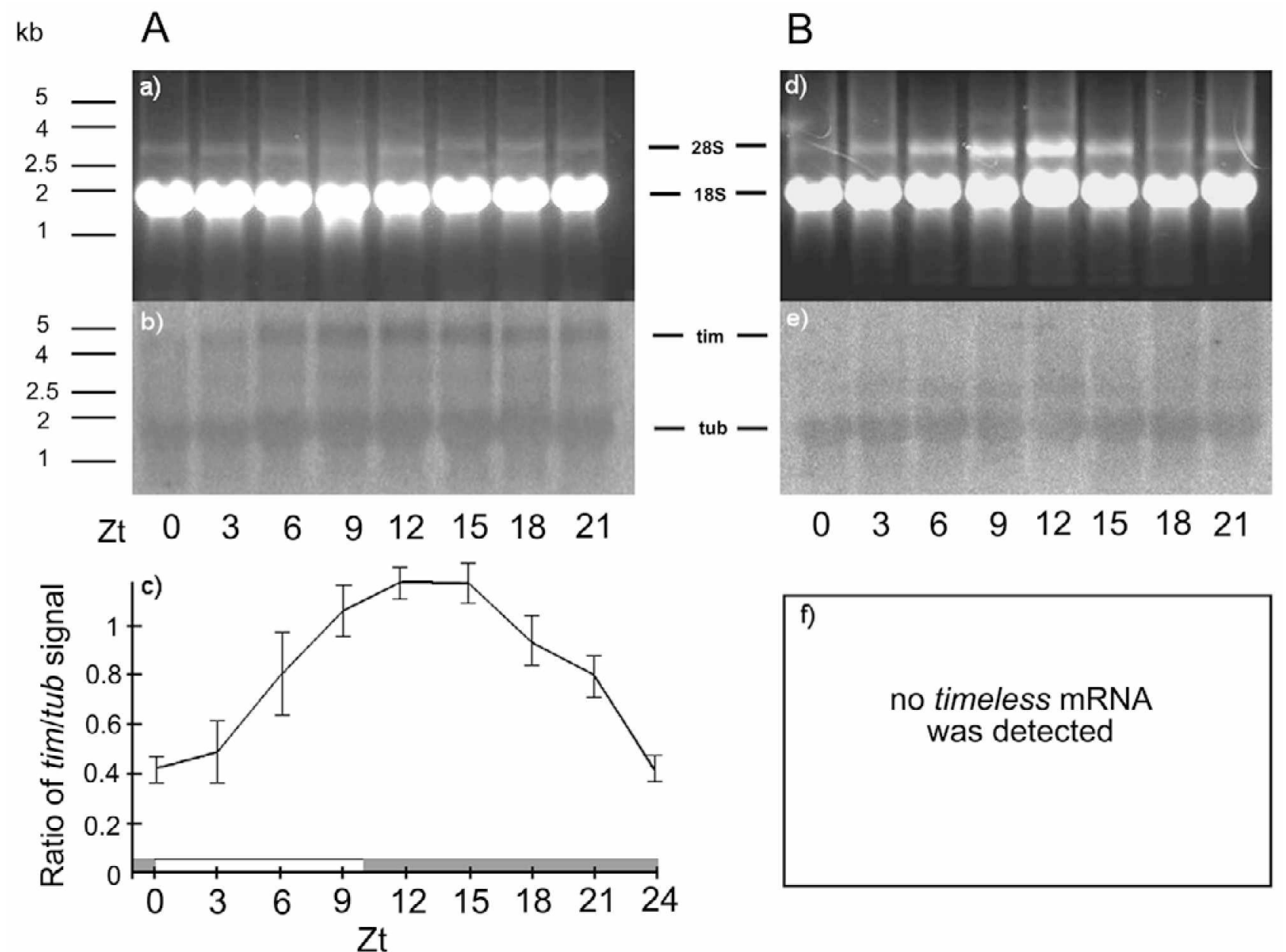

Fig. 2. Northern hybridization analysis of the expression of timeless gene in adult heads of Chymomyza costata of the (A) wildtype (Sapporo) and (B) $n p d$-mutant (NPD) strains. Samples of total RNA were taken at 3h-intervals of Zeitgeber time (Zt) (white and dark portions of the $x$-axis represent light and dark phases, respectively). Total RNA was loaded on formaldehyde-agarose gel

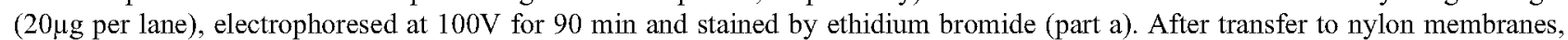
RNA was hybridized sequentially with ${ }^{32}$ P-labeled probes for timeless (tim) and ß-tubulin (tub) (part b). The quantified radioactive signal of timeless hybridization (normalized to signal of B-tubulin) is plotted in part $c$ ) of the Figure. Parts a) and b) depict one of three replications of the experiment; part c) shows mean \pm S.E. results of three replications.

The timeless and B-tubulin cDNA clones were used as sources for probes for Northern blot analysis. The timeless probe, isolated from the clone by EcoR I digestion, had 321 nucleotides. The deduced sequence of 107 amino acids corresponded to amino acids $610-716$ of $D$. melanogaster TIMELESS protein and $87 \%$ of amino acids were identical between the two insect species. The B-tubulin probe was isolated from the clone by digestion using Pst I and $X b a$ I restriction enzymes. It consisted of 665 nucleotides. The deduced sequence of 221 amino acids corresponded to amino acids 84-304 of D. melanogaster ß-TUBULIN protein and $90 \%$ of amino acids were identical between the two insect species.

\section{Sequencing the full-length timeless cDNA}

Two timeless-gene-specific primers tim 15 , tim16 (Table 1) were designed based on cDNA sequence of the cloned timeless fragment. The upstream and downstream coding regions were amplified by RT-PCR with two sets of primers: upstream: tim16, tim21; downstream: $\operatorname{tim} 15, \operatorname{tim} 28$ (Table 1). 5'- and 3'unknown sequences flanking to the coding region were amplified by 5' Rapid Amplification of cDNA Ends (5'RACE) and 3'RACE Systems, respectively, according to the manufacturer's instructions (GibcoBRL). Gene-specific primers tim31, tim35 (Table 1) were used to prime the target sequences. RT-PCR products, digested with or without EcoR I, were cloned into pBluescript SK $(+)$ (Stratagene) or pGEM-T Easy (Promega) vectors. The clones carrying target genes were cultured in Terrific Broth. The plasmid DNA was extracted by the standard alkali lysis and purified by precipitation with polyethylene glycol (Sambrook et al., 1989).

Purified plasmid DNA was sequenced by using THERMO Sequenase II dye terminator cycle sequencing kit (Amersham Pharmacia Biotech). Cycle sequencing reactions were carried out according to the manufacturer's instructions. The precipitated products were re-dissolved in sample loading buffer (Amersham Pharmacia Biotech) and were analyzed on ABI PRISM 377 DNA Sequencer (Applied Biosystems).

\section{Northern blot analysis}

Adult flies of the Sapporo and NPD strains maintained at $18^{\circ} \mathrm{C} / \mathrm{SD}$ for 7 days (since adult emergence) were subjected to Northern blot analysis. The fly heads (100/sample) were collected at 3-hour intervals of Zeitgeber time throughout the photoperiodic cycle. Total RNA was extracted by the standard 

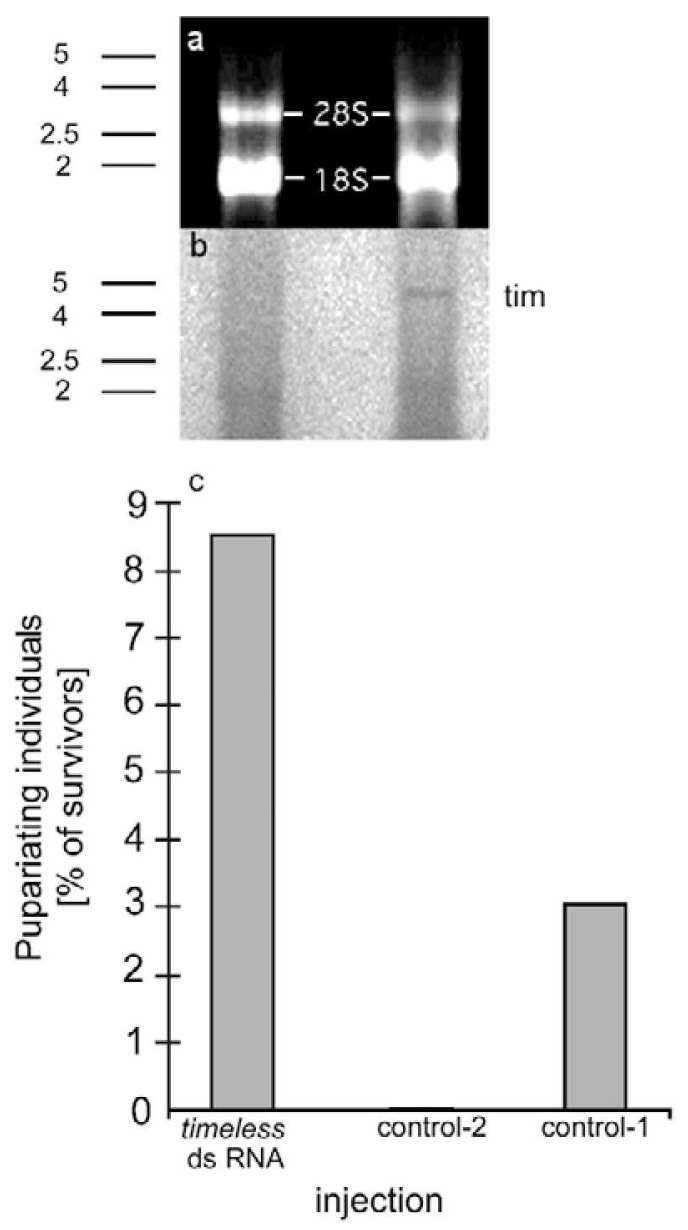

Fig. 3. RNA interference. Total RNA was extracted from 15 pupariating individuals of Chymomyza costata (wild-type, Sapporo strain) that were differently treated in early embryonal stage (from the left): injected with the timeless dsRNA dissolved in injection buffer under halocarbon oil; treated with halocarbon oil without any injection (control-2); injected with injection buffer alone under halocarbon oil (control-1). The upper part (a) shows total RNA (5.5 $\mu \mathrm{g}$ in each lane) separated on formaldehyde-agarose gel and stained by ethidium bromide. The middle part (b) shows Northern hybridization with ${ }^{32} \mathrm{P}$ labeled timeless probe on a nylon membrane. The lower part (c) show proportions of pupariating individuals in each treatment (total numbers of survivors were: 504 after dsRNA injection; 258 in control-2; 82 in control-1).

protocol described above. Each aliquot $(20 \mu \mathrm{g})$ was separated by formaldehyde-agarose gel electrophoresis, transferred to nylon membranes (Hybond- $\mathrm{N}^{+}$, Amersham) and hybridized with radioactive ${ }^{32} \mathrm{P}$-labeled probe for timeless. After washing out the timeless probe, the separated RNA on nylon membranes was hybridized with $\beta$-tubulin ${ }^{32} \mathrm{P}$-labeled probe. The membranes were exposed to a BAS-1500 Imaging Plate (Fujifilm, Japan) for 2 hours and quantitatively analyzed using the NIH Image software (http://rsb.info.nih.gov/nih-image/).

\section{RNA interference}

The RNAi method (Kennerdell \& Carthew, 1998, 2000) was applied in an attempt to silence the timeless gene expression in the Sapporo strain larvae and observe its effect on photoperiodic phenotype (developmental response to short days). Template
TABLE 1. Primer sequences.

\begin{tabular}{ll}
\hline Purpose name & \multicolumn{1}{c}{ Sequence $\left(5^{\prime} \rightarrow 3^{\prime}\right)$} \\
\hline Cloning & \\
tim11 & AAAGAATTCTGGGGNGTNACNATGGT \\
tim12 & AAAGAATTCDATRTGRTGCATCAT \\
tub1 & AAGAGCTCTGGAGCCMGGYACSATGGACTCKGT \\
tub2 & AAGAGCTCGTCTTCACGTTGTTGGGGATCCA \\
Sequencing cDNA & \\
tim15 & GCTCAAGGGCTATAACTATTTGG \\
tim16 & ACCACAAGATGCATGCGACGC \\
tim21 & AAGAATTCATGGAYTGGTTRCTNGCNAC \\
tim28 & AAGAATTCRTCYTCRTCRCTNACRTACAT \\
RACE & \\
tim31 & GCTTAAAGCGCTCTTGGTTAGCTGTGC \\
tim35 & AAGAATTCGGTGGCATCTATATACGAAAA \\
Sequencing intron \\
tim23 & AAGAATTCACCCAATGCATYGGGGCTGACCACAT- \\
AGGT & AAGAATTCNNNAGGGTAAG \\
int1 & AAGAATTCAAGCTGCTAGTCGCCATAGCAG \\
tim26 & AAGGATTCGTGTTATCATCCTGCCACG \\
tim27 & AAGAATTCA \\
Genetic linkage analysis \\
tim24 CGACACGTTGAACGCTCATACG \\
tim29 & TTCAGAGCGTGATTTTGCAGCAGTC \\
\hline
\end{tabular}

DNA for synthesis of double-stranded (ds) RNA was produced by a standard PCR using primers tim $16, \operatorname{tim} 21$ (Table 1) with the $\mathrm{T} 3$ and $\mathrm{T} 7$ promoters added to primer sequences [reaction conditions: 5U Taq DNA polymerase (Takara, Japan) in $200 \mu \mathrm{l}$ reaction mixture $\left(10 \mathrm{mM}\right.$ Tris- $\mathrm{HCl}, 50 \mathrm{mM} \mathrm{KCl}, 1.5 \mathrm{mM} \mathrm{MgCl}_{2}$, $0.8 \mathrm{mM}$ dNTP, $\mathrm{pH} 8.3$ ); thermal conditions: $95^{\circ} \mathrm{C}, 3 \mathrm{~min} ; 30$ cycles of $94^{\circ} \mathrm{C}, 30 \mathrm{sec}, 60^{\circ} \mathrm{C}, 30 \mathrm{sec}, 72^{\circ} \mathrm{C}, 5 \mathrm{~min}$ ]. Single strand timeless RNA was transcribed using the T3,T7 RNA polymerase on the genomic DNA template according to the instruction manual (Stratagene). Remaining DNA was digested by DNAase (Roche). Single strands of RNA with T3 and T7 ends were mixed in injection buffer [IB, $5 \mathrm{mM} \mathrm{KCl}, 0.1 \mathrm{mM}$ $\mathrm{NaH}_{2} \mathrm{PO}_{4}$, pH 6.8 (Rubin \& Spradling, 1982)], heated at $100^{\circ} \mathrm{C}$ for $1 \mathrm{~min}$, and kept at room temperature for $18 \mathrm{~h}$. Aliquots were frozen at $-80^{\circ} \mathrm{C}$. Resulting dsRNA had 1966 nucleotides, the deduced sequence of 655 amino acid corresponded to amino acids 24-711 of $D$. melanogaster TIMELESS protein (76\% amino acids were identical between the two insect species). The dsRNA was dissolved in IB and approximately 0.2 fmol (ca 0.3 $\mu \mathrm{l}$ of IB) aliquots of dsRNA were injected, under halocarbon oil (Sigma), into the ventral side of the posterior domain of $C$. costata embryos, Sapporo strain. The embryos were not more than $1 \mathrm{~h}$ old. Control embryos were either injected with injection buffer alone (control-1) or were only exposed to halocarbon oil (control-2). After the treatment, the embryos and larvae were reared under short-day conditions, which promote entrance into diapause (no-pupariation) in untreated Sapporo strain larvae. Those dsRNA-treated individuals that pupariated ("positive" individuals) were collected in the stage of white puparium and total RNA was extracted for the analysis of the presence of timeless mRNA transcripts by Northern ( 15 puparia were pooled for one sample, see above for RNA isolation).

\section{Sequencing the intron}

Sequential Thermal Asymmetric Interlaced (TAIL)-PCR (Liu et al., 1995) was carried out to determine genomic sequence flanking to the timeless coding region. The genomic DNA from the wild-type $C$. costata was amplified in a $50 \mu 1 \mathrm{PCR}$ buffer [(500ng DNA, 0.8mM dNTP, 2.5U of Taq DNA polymerase (Takara, Japan)] using $0.2 \mu \mathrm{M}$ of the timeless-specific antisense primer tim 23 and $1 \mathrm{mM}$ of a degenerate sense primer int1 (Table 1). After $3 \mathrm{~min}$ of denaturation at $95^{\circ} \mathrm{C}$, the DNA fragments were amplified for 5 cycles of $60 \mathrm{sec}$ at $94^{\circ} \mathrm{C}, 60 \mathrm{sec}$ at $65^{\circ} \mathrm{C}$, 
tim Sap -1399:GTGTTATCATCCTGCCACGTTACGTAGCTGCACATTGCATTGACTGTGGCTGTCCGTCTC

tim SaP :CATATAACTGCTTGAGTGACAGTTACTGCAGTTAACATGCTACTTGTACGTGGTTACATG

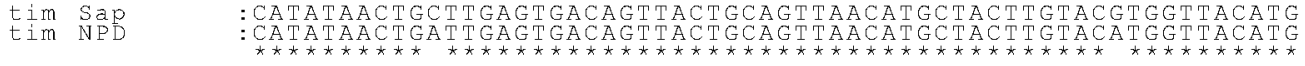
$\begin{array}{ll}\text { tim Sap } & \text { :CATTCTTGAGATTTCTTTGACATATAGTACTGTGAAAAGGTGGTGGCCAGCACATAGGTA } \\ \text { tim NPD } & \text { :CATTCTGGGTTTCTTGACATATAGACTGAGATGGTGTGGCAGCACTTACGTA }\end{array}$ $\operatorname{tim}_{\operatorname{tim}} \operatorname{Sap}$ tim24 2 GCTATTTTATATGCGACACGTGACGCTTATACGTTGTTGGGATTCACAATGAATA

$\operatorname{tim} S \operatorname{Sap}$
tim $\mathrm{NPD}$ $\begin{array}{ll}\operatorname{tim} & \operatorname{Sap} \\ \text { tim } & \mathrm{NPD}\end{array}$

$\operatorname{tim} \frac{\operatorname{Sap}}{\operatorname{SaD}}$

$\begin{array}{ll}\text { tim } & \text { Sap } \\ \text { tim } & \text { NPD }\end{array}$

$\begin{array}{ll}\text { tim } & \text { Sap } \\ \text { tim NPD }\end{array}$

$\begin{array}{ll}\text { tim } & S a p \\ \text { tim } & \text { NPD }\end{array}$

$\begin{array}{ll}\text { tim } & \text { Sap } \\ \text { tim NPD }\end{array}$

tim
tim $\mathrm{Sap}$
NED

$\begin{array}{ll}\text { tim } & \text { Sap } \\ \text { tim NPD }\end{array}$

$\begin{array}{ll}\text { tim } & \text { Sap } \\ \text { tim } & \text { NPD }\end{array}$

$\begin{array}{ll}\text { tim } & \text { Sap } \\ \text { tim NPD }\end{array}$

$\begin{array}{ll}\text { tim } & \text { Sap } \\ \text { tim NPD }\end{array}$

$\begin{array}{ll}\text { tim } & \text { Sap } \\ \text { tim NPD }\end{array}$

$\begin{array}{ll}\text { tim } & \text { Sap } \\ \text { tim } & \text { NPD }\end{array}$

$\begin{array}{ll}\text { tim } & \text { Sap } \\ \text { tim NPD }\end{array}$

tim Sap

tim Sap
tim NPD

$\begin{array}{ll}\text { tim } & \text { Sap } \\ \text { tim NPD }\end{array}$

$\begin{array}{ll}\text { tim } & \text { Sap } \\ \text { tim NPD }\end{array}$

$\begin{array}{ll}\text { tim } & \text { Sap } \\ \text { tim } & \text { NPD }\end{array}$

$\begin{array}{ll}\text { tim } & \text { Sap } \\ \text { tim } & \text { NPD }\end{array}$

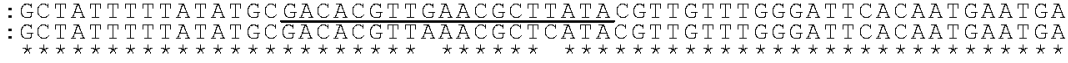

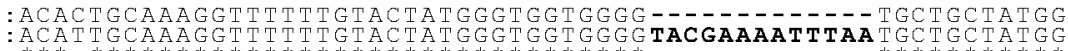
:

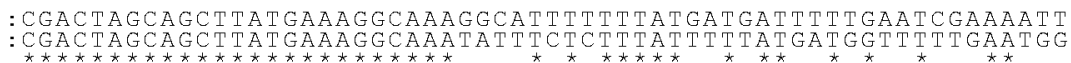

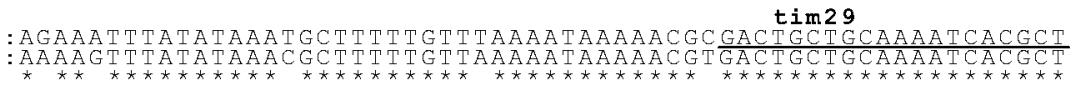
CTGAAAAATATTGAACCAAGAAATATTCTCATCTGAATTAATTATGCAAAAACTACGCAA
:TGAAAAGATTGAACAAAAATATTCTCATTGAATAATTAGCACAAACTACGCAA TATTCATCATCTATTAAATAAACATTGGCTATATATTTTAATTATTTAGTACATATTCA

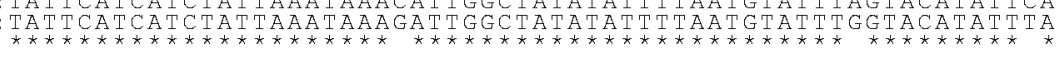
:CAGAGTTAGCCGTCGTTATTGCCAACTGAGTTAATATTCGATATTTTTTAGTCCCTCTA
:AAGAGGTAGCCGTCGTTATTGCCAACTGAGTTATTATTCGATATTTTTTTAGTTCCTCTA GAGTTTGCCATATGCAATTTTTTGTTACTTTATAATGCCTATAACTAGTGGACGACCAAG

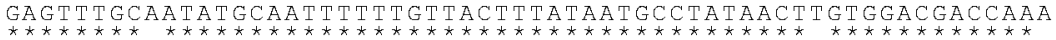

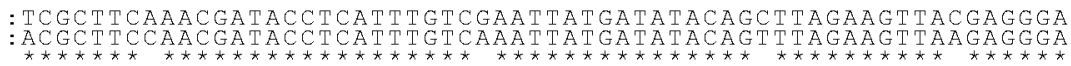
:ACAGATG--CA----CTTCTTTGTTGCATTAACTTCTAGTGGAGCATAGGGCCTTCCGAA

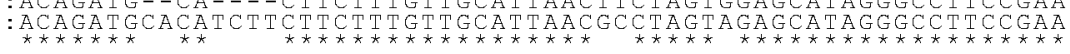
:GATAAACATAAATACAGACATTTATGTCAAAAACAAAACACTCCTTTTTATTCGCCGTAG

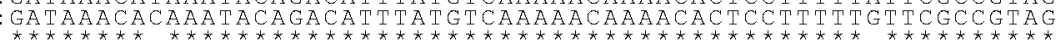
:CCGTGGCTAATTCTTTTAAAAAGCACTGCTCATCTTCAAGACTTACTCATTTAAGAGTT

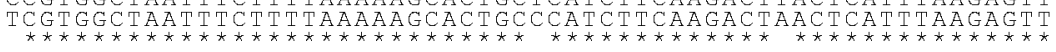
:AAAAAGCTTTCTTATTAAAAATCAATAGAATTTACGAGCAGAAGAC-- TGTATTAAA

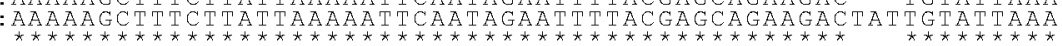

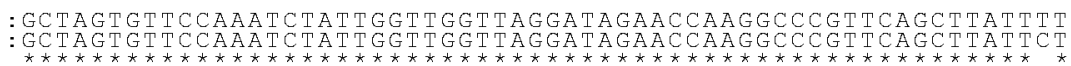
:GTTGTCGGAGTTGTCTTCAAATTGCGACACTTCTTTTTATGTCTCAAACCAATTTTTTTT

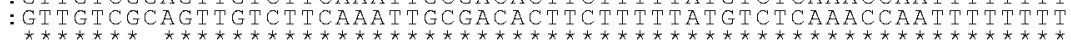
:AAGTTTTAGAATGCACATCAAAAATGTAAAGAATTCTCTACTTAAAAAGATTATCTCCA AAGTTTTAGAATGCACATCAAAAATGTAAAGAATTCTTCTACTTAAAAAGATTATCTCCA

:TGTTGGAAATGCTAATTCTTTGTAAAGCTTATTGAATATAAAATATTCCGTTAAAGT :TGTTGGAAAACGCAAATTTCTTTTTAAAGCTTATTGAAATATAAAATATTTCGTTTGAGT :AAACTGCATTTAAAATAATATTATCTCATCCAGTTGCAGCCCCAGCCTGCTTACAAA-GG

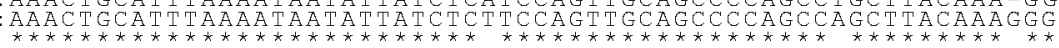
ACCTGTAGCTGGCCTAAACCCTATTAACTAGGGTTGCGTTTCATGCTCTACGCTGATCAT

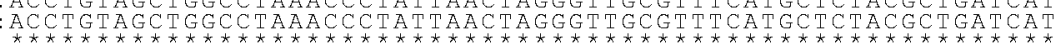
GTGCTGCAAGTGGCTACAAATAATAAATTGTGTCCAAAATATCAACGTTATATACAAATC

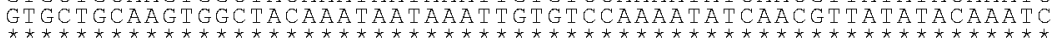

:CAAGTATATCATACCAGAAACACACATAAGCGCCGGGCTATGGACTGGTTACTCGCAA :CAAGTATTATCATACCAGAAACATCACATAAGCGCCGGGCTATGGACTGGTTACTCGCAA $M \quad D \quad W \quad L \quad L \quad A$

$=============$ coding sequence $============================1$
CGCCACAGTTGCATAGCGCCTTCTCATCATTGGGGGCGCTTGTGGGTGACACCTATGTGG $\underset{\star}{: \text { CGCCACAATTGCATAGCGCCTTCTCATCATTGGGCGCGCTTGTGGGTGACACCTATGTGG }}$

$\operatorname{tim}$
tim $\mathrm{Sap}$

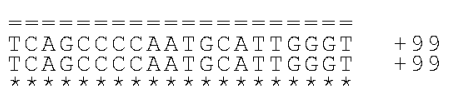

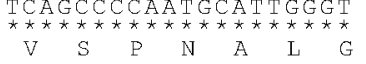


and $3 \mathrm{~min}$ at $72^{\circ} \mathrm{C}$ followed by 15 cycles of $30 \mathrm{sec}$ at $94^{\circ} \mathrm{C}, 60$ sec at $68^{\circ} \mathrm{C}, 3 \mathrm{~min}$ at $72^{\circ} \mathrm{C}, 30 \mathrm{sec}$ at $94^{\circ} \mathrm{C}, 60 \mathrm{sec}$ at $68^{\circ} \mathrm{C}, 3 \mathrm{~min}$ at $72^{\circ} \mathrm{C}, 30 \mathrm{sec}$ at $94^{\circ} \mathrm{C}, 60 \mathrm{sec}$ at $44^{\circ} \mathrm{C}$, and $3 \mathrm{~min}$ at $72^{\circ} \mathrm{C}$. Further sequencing for the non-coding region was tried with a new gene-specific primer tim 26 and int1 (Table 1). The TAIL-PCR products were digested by EcoR I, cloned into pBluescript $\mathrm{SK}(+)$ (Stratagene) and sequenced as described above.

Genomic DNA of timeless gene from $n p d$-mutants was amplified by a standard PCR with a set of timeless-specific primers tim27, tim23 (Table 1). The PCR products were cloned into pBluescript SK $(+)$ and sequenced as described above.

\section{Genetic linkage analysis}

Genetic linkage analysis was performed to examine the coinheritance of the NPD phenotype (no-diapause induction in response to short days) and a mutant allele of timeless gene (as revealed by intron sequencing). Females of $n p d$-mutant flies were mated with wild-type Sapporo strain males and the reciprocal crosses were also performed. F1 progeny were reared under long-day conditions (16h light : $8 \mathrm{~h}$ darkness, $18^{\circ} \mathrm{C}$ ) to prevent larval diapause and the adults were intercrossed. F2 progeny were reared under short days to screen for the NPD phenotype: those larvae that pupariated under short days (i.e. did not enter diapause) were recognized as npd individuals; those larvae that had not pupariated within 40 days after oviposition (i.e. entered diapause) were recognized as wild-type individuals. Later, the diapausing larvae were exposed to constant light $\left(24 \mathrm{~h}\right.$ light : $0 \mathrm{~h}$ darkness, $18^{\circ} \mathrm{C}$ ) to terminate their diapause and allow development of adults. DNA was extracted from each individual fly and the fragment of intron-DNA in the 5 '-leader sequence of timeless was amplified by a standard PCR with a set of primers tim24, tim29 (Table 1, Fig. 4). The PCR products were separated on $8 \%$ polyacrylamide gel by electrophoresis to analyze the length difference (a 13-bp insertion in mutated timeless allele).

\section{RESULTS}

\section{Full-length sequence of timeless cDNA}

The timeless cDNA of $C$. costata (wild-type, Sapporo strain) had 5295 nucleotides (data not shown, see EMBL/GenBank/DDBJ accession number: AB073724). It consisted of 3 main regions: 5 '-leader sequence (453bp), coding sequence (4128-bp) and 3'-untranslated region (714-bp). The sequence coded for 1355 amino acids, which corresponded to amino acids 24-1421 of $D$. melanogaster's TIMELESS protein (Fig. 1).

\section{Northern blot analysis}

In the wild-type Sapporo strain, Northern hybridization indicated that the abundance of timeless mRNA transcripts oscillates on a daily basis in fly heads. The maximum abundance of mRNA transcripts was detected during the first half of the dark phase ( $\mathrm{Zt} \mathrm{12-15).} \mathrm{The}$ minimum abundance was registered during "late night" and "early morning" ( $\mathrm{Zt} 0-3$ ) (Fig. 2A). In the NPD strain, no timeless mRNA transcripts were detectable throughout the photoperiodic cycle (Fig. 2B).

\section{RNAi}

Double-stranded (ds) timeless RNA was injected into 5562 early embryos of the wild-type Sapporo strain. Another 472 embryos were injected with injection buffer (IB) alone (control-1) and 270 embryos were only treated with halocarbon oil, without any injection (control-2). Surviving larvae were reared under short-day conditions to screen their photoperiodic phenotype. Results are summarized in Fig. 3. None of the surviving control-2 larvae pupariated (all larvae entered diapause) and their timeless mRNA was detectable by Northern. Only about 17 or $9 \%$ of embryos survived the treatment in dsRNA injected or IB-injected (control-1) variants, respectively. Three out of $82(3.65 \%)$ surviving control-1 larvae pupariated and remaining larvae entered diapause. The number of pupariated control-1 larvae was too low to perform a reliable Northern analysis of timeless mRNA (our preliminary experiments showed that $10-15$ puparia is a minimum number to obtain enough total RNA). Thus, we can not decide whether the pupariation in control-1 larvae resulted from the disruption of transcription of timeless gene or from some non-specific effect of IB injection. Forty-six out of $504(9.13 \%)$ surviving dsRNA-treated larvae pupariated and their timeless mRNA was not detectable by Northern (Fig. 3). Pupariating individuals were considered as having lost their photoperiodic response after injections with either timeless dsRNA or IB.

\section{Sequence of intron in 5'-leader region of timeless cDNA}

About $1.4 \mathrm{Kbp}$ genomic DNA fragment flanking to the timeless coding region was amplified by TAIL-PCR (Fig. 4). Comparison of intron sequences between the Sapporo and NPD strains revealed that npd-mutants carry a different, potentially "deficient", timeless allele, which we call here timeless ${ }^{\text {npd }}$. The timeless ${ }^{n p d}$ allele shows, in addition to many point-substitutions, a remarkable 13-bp insertion. This insertion sequence was used as a marker of a time$l e s s^{n p d}$ allele in a genetic linkage analysis.

\section{Genetic linkage analysis}

The npd-mutant flies (NPD strain), homozygous for the timeless $^{\text {npd }}$ allele (with 13-bp insertion in intron), were reciprocally mated with the wild-type flies (Sapporo strain), homozygous for the normal timeless allele. The wild-type and npd photoperiodic phenotypes were distinguished based on their response to short days (diapause induction or not, respectively). Flies carrying the deficient and/or normal timeless alleles were distinguished by the length of PCR fragments amplified with timeless-intronspecific primers (218-bp or 205-bp, respectively). Pedigrees in Fig. 5a) and b) show the inheritance of photoperiodic phenotypes and the dimorphic timeless

Fig. 4. Alignment of intronic DNA sequences of timeless alleles from wild-type (Sapporo strain, Sap) and npd-mutant (NPD strain) of Chymomyza costata (alignment was performed using GENETYX-MAC software, Software Development, Tokyo, Japan). The intron is located in the 5'-leader sequence (indicated by single line above the sequence) flanking to the coding region (indicated by double line) of timeless gene. A remarkable $13 \mathrm{bp}$-insertion found in the sequence from NPD strain (timeless ${ }^{\text {npd }}$ allele) is indicated by bold-faced letters. Primers used for PCR amplification of the insertion regions are indicated by underlines. Asterisks $(*)$ indicate identical nucleotides. 
a)

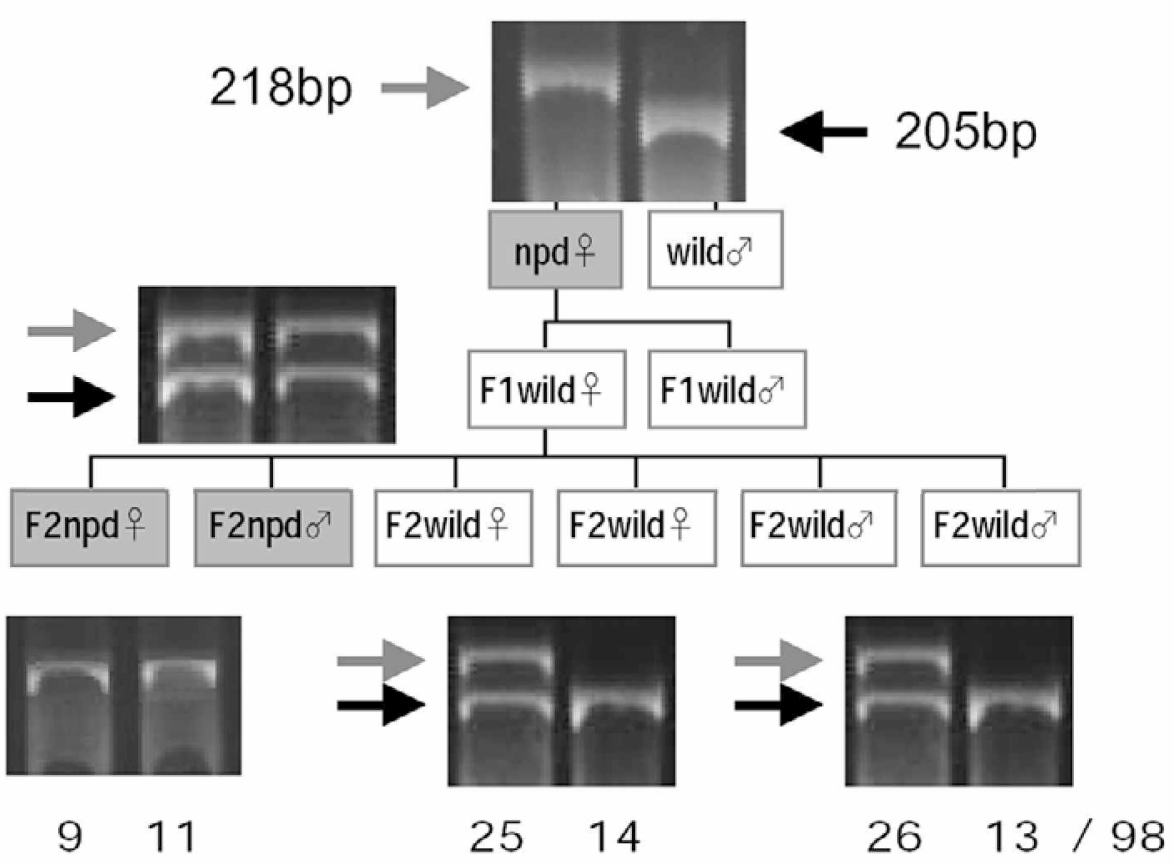

b)

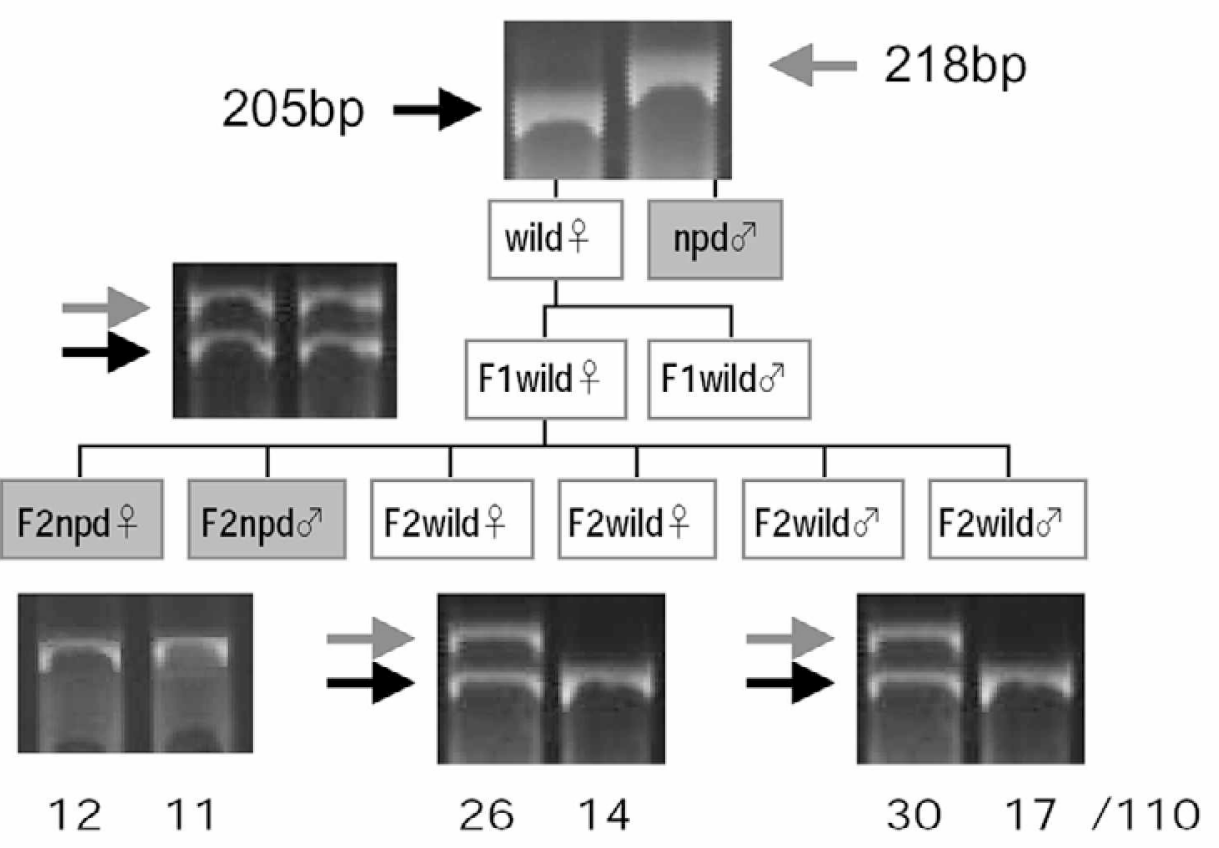

Fig. 5. Genetic linkage analysis between the photoperiodic phenotype and a dimorphic allele of timeless gene in the reciprocal hybrids between the wild-type flies (Sapporo strain) and $n p d$-mutants (NPD strain) of Chymomyza costata. Photoperiodic phenotype is either wild-type (wild, white box; entrance to diapause in response to short-day signal) or $n p d$-mutant (npd, gray box; no response to short-day signal). The timeless allele is either wild-type (yielding a 205-bp DNA fragment after PCR amplification) or $n p d$-mutant type (timeless ${ }^{\text {npd }}$, yielding a 218-bp DNA fragment due to the presence of a 13-bp insertion). Pedigrees show the inheritance of the two traits in the progeny of reciprocal hybrids: (a), npd-mutant female was mated with wild-type male; (b) reciprocal cross. Individual flies of the F2 progeny were tested for the presence of each of the two traits (numbers given below). The npd-mutant photoperiodic phenotype was strictly co-inherited with the timeless $^{\text {npd }}$ allele.

alleles in F1 and F2 progeny. In both pedigrees, which reciprocally differed in parental genotypes, F1 progeny showed wild-type phenotype and carried both deficient and normal timeless alleles (heterozygous). In F2 progeny, which was produced by intercrosses between $\mathrm{F} 1$ siblings, the phenotypes and genotypes were distributed approximately according to the Mendelian laws $(1: 2: 1$ for genotypes and 3:1 for phenotypes). Importantly, a nonphotoperiodic (NPD) phenotype was in all cases (21 females, 22 males) accompanied by the presence of homozygotism for a deficient timeless ${ }^{\text {npd }}$ allele. Individuals that were either heterozygous (51 females, 56 
males) or homozygous for normal timeless allele (28 females, 30 males) always showed a wild-type photoperiodic phenotype.

\section{DISCUSSION}

In this study, full-length cDNA and amino acid sequences of the structural homologue of D. melanogaster's timeless gene were obtained from a closely related fly, Chymomyza costata. The $62 \%$ of amino acids were identical between the two species. In several conserved domains, the structural homologuey of amino acid sequences was much higher: $88 \%$ in PER interaction domain I (PID I), 75\% in PID II, and 90\% in nuclear localization signal (NLS) domain. In addition, a 32 aa region that is important for restoring wild-type rhythms (Ousley et al., 1998) was also highly conserved (91\% of amino acids were identical between the two species). An acidic domain, thought to be involved in the activation of transcription factor in D. melanogaster, is rich $(60 \%)$ in acidic amino acids, $\mathrm{E}$ (glutamic acid) and $\mathrm{D}$ (aspartic acid) (Myers et al., 1995). A corresponding region in $C$. costata, however, contained only $24 \%$ acidic amino acids, and the similarity between the two species was quite low (19\%). The cytoplasmic localization domain (CLD) at the C-terminus was also less conserved (49\% similarity between $C$. costata and D. melanogaster). Reduced conservation in the CLD and acidic domains of TIMELESS was also observed among other drosophilid species (Ousley et al., 1998). The sites to which im $^{S L}$ (which shortens the wild-type period by half an hour; Rutila et al., 1996), $t^{i m}{ }^{L I}$ (lengthens the circadian rhythm; Rothenfluh et al., 2000), $\operatorname{tim}^{L 2}$ (produces $26.3 \mathrm{~h}$ circadian rhythm; Rothenfluh et al., 2000) and tim $^{\text {rit }}$ (alters free-running periods in a temperature-dependent manner; Matsumoto et al., 1999) mutations have been mapped in D. melanogaster were also conserved in C. costata.

In the wild-type (Sapporo) strain of $C$. costata, the abundance of mRNA transcripts of this gene were shown to oscillate on a daily basis, in phase with the transcripts of another clock gene, period (Kostal \& Shimada, 2001). Similar oscillations in period and timeless transcription were found in lateral neurons of the brain of $D$. melanogaster and proved to represent a central feature of its circadian clock (Sehgal et al., 1994; Allada et al., 1998; Darlington et al., 1998; Rutilla et al., 1998; Dunlap, 1999; Harmer et al., 2001).

No mRNA transcripts, however, were detected by Northern blot analysis in the non-photoperiodic-diapause mutants (NPD strain) of C. costata (irrespective of Zeitgeber time of RNA sampling). Thus, it seems that the rate of timeless transcription is either zero or severely diminished in $n p d$-mutants (relatively low sensitivity of Northern does not allow us to distinguish between the two possibilities). Mal-functioning of the central circadian clock system in the brain of npd-mutants is highly probable because: (1) no daily/circadian oscillations of period mRNA transcripts were found (Kostal \& Shimada, 2001); and (2) no/diminished expression of timeless gene was detected (this study). Such a striking difference in timeless expression between the two strains of $C$. costata appears interesting when related to npd-mutant's circadian and photoperiodic phenotypes. NPD strain flies are non-photoperiodic and behaviourally arrhythmic (Riihimaa \& Kimura, 1988, 1989; Kostal \& Shimada, 2001) and it was confirmed by classical crossbreeding experiments that both traits were caused by mutation in a single autosomal gene locus npd (Riihimaa \& Kimura, 1989; Riihimaa, 1996; Lankinen \& Riihimaa, 1992, 1997).

The above results led us to hypothesize that the npd locus might code for a functional element, which is shared by circadian and photoperiodic clock systems. Some results obtained in this study indicate that TIMELESS protein might be such a linking element. First, selective disruption of timeless gene transcription (RNAi) in the wild-type flies resulted, in a certain proportion of survivors at least, in adoption of a $n p d$ photoperiodic phenotype (i.e. no response to short days). The results of RNAi experiments, however, are difficult to interpret conclusively because of: (1) low survival rate after injection of timeless dsRNA (ca. 17\%); (2) low rate of specific response (loss of photoperiodic sensitivity) to dsRNA (ca. $9 \%$; and (3) relatively high non-specific response to the injection buffer alone (ca. 3.7\%). All three problems (1-3) are more or less typical for RNAi methodology (Kennerdell \& Carthew, 1998, 2000), especially when the phenotypic effect is to be observed some time after the injection of dsRNA. In our case, the pupariation of $C$. costata typically occurred 21 days or more after the injection, which makes the persistence of RNAi effect problematic. Second, the existence of dimorphism in the timeless allele (a 13-bp insertion found in intron of $n p d$ mutants in this study) allowed performing genetic linkage analysis of inheritance of timeless alleles and photoperiodic phenotype. In total, 208 F2 hybrids of Sapporo and NPD strains were individually analyzed and it was found that the deficient allele of timeless gene (timeless ${ }^{\text {npd }}$ ) is strictly co-inherited with the non-photoperiodic phenotype.

In conclusion, introductory results presented in this paper imply that there might exist a close functional linkage between circadian and photoperiodic time measurement systems in the drosophilid fly C. costata. At present, the npd locus, which could be coding for TIMELESS protein, seems to be a candidate for such a linking element. Our ongoing work is focused on testing this hypothesis.

ACKNOWLEDGEMENTS. Part of the study was performed during the stay of J.P. at Hokkaido University, Sapporo (JSPS Postdoctoral Fellowship No. P99328). The work carried out in Czech Republic was supported by the Grant Agency of the Czech Republic (grants No. 204/02/P008 and No. 206/02/0900).

\section{REFERENCES}

Allada R., White N.E., So W.V., Hall J.C. \& Rosbash M. 1998: A mutant Drosophila homologue of mammalian clock disrupts circadian rhythms and transcription of period and timeless. Cell 93: 791-804. 
BüNNING E. 1936: Die endogene Tagesrhythmik als Grundlage der photoperiodischen Reaktion. Ber. Dt. Bot. Ges. 54 590-607.

Darlington T.K., Wager-Smith K., Ceriani M.F., Staknis D., Gerakis N., Steeves T.D.L., Weitz C.J., Takahashi J.S. \& KAY S.A. 1998: Closing the circadian loop: CLOCK-induced transcription of its own inhibitors per and tim. Science $\mathbf{2 8 0}$ : $1599-1603$

Denlinger D.L. 2000: Molecular regulation of insect diapause. In: Storey K.B. \& Storey J.M. (eds): Environmental Stressors and Gene Responses. Elsevier Science, Amsterdam, pp. 259-275.

Denlinger D.L. 2002: Regulation of diapause. Annu. Rev. Entomol. 47: 93-122.

Dunlap J.C. 1999: Molecular bases for circadian clocks. Cell 96: $271-290$

GoldMan B.D. 2001: Mammalian photoperiodic system: formal properties and neuroendocrine mechanisms of photoperiodic time measurement. J. Biol. Rhythms 16: 283-301.

Goto S.G. \& Denlinger D.L. 2002: Shrot-day and long-day expression patterns of genes involved in the flesh fly clock mechanism: period, timeless, cycle and cryptochrome. $J$. Insect Physiol. 48: 803-816.

Harmer S.L., Panda S. \& Kay S.A. 2001: Molecular bases of circadian rhythms. Annu. Rev. Cell Dev. Biol. 17: 215-253.

KenNerdell J.R. \& CARTHEW R.W. 1998: Use of dsRNAmediated genetic interference to demonstrate that frizzled and frizzled2 act in the wingless pathway. Cell 95: 1017-1026.

Kennerdell J.R. \& CARTHEW R.W. 2000: Heritable gene silencing in Drosophila using double-stranded RNA. Nat. Biotechnol. 18: 896-898.

Konopka R.J. \& Benzer S. 1971: Clock mutants of Drosophila melanogaster. Proc. Natl. Acad. Sci. USA 68: 2112-2116.

Kostal V., Shimada K. \& Hayakawa Y. 2000a: Induction and development of winter larval diapause in a drosophilid fly Chymomyza costata. J. Insect Physiol. 46: 417-428.

Kostal V., Noguchi H., Shimada K. \& Hayakawa Y. 2000b: Circadian component influences the photoperiodic induction of diapause in a drosophilid fly, Chymomyza costata. $J$. Insect Physiol. 46: 887-896.

Kostal V. \& Shimada K. 2001: Malfunction of circadian clock in the non-photoperiodic-diapause mutants of the drosophilid fly, Chymomyza costata. J. Insect Physiol. 47: 1269-1274.

LAKOVAARA S. 1969: Malt as a culture medium for Drosophila species. Drosoph. Inf. Serv. 44: 128.

LANKINEN P. 1986: Genetic correlation between circadian eclosion rhythm and photoperiodic diapause in Drosophila littoralis. J. Biol. Rhythms 2: 101-118.

LANKINEN P. \& RimimaA A.J. 1992: Weak circadian eclosion rhythmicity in Chymomyza costata (Diptera: Drosophilidae), and its independence of diapause type. J. Insect Physiol. 38 : 803-811.

LANKINEN P. \& RIIHIMAA A.J. 1997: Effects of temperature on weak circadian eclosion rhythmicity in Chymomyza costata (Diptera: Drosophilidae). J. Insect Physiol. 43: 251-260.

LiU Y.G., Mitsukawa N., Oosumi T. \& WhitTier R.F. 1995: Efficient isolation and mapping of Arabidopsis thaliana T-DNA insert junctions by thermal asymmetric interlaced PCR. Plant J. 8: 457-463.

Loudon A.S.I., Ihara N. \& Menaker M. 1998: Effect of a circadian mutation on seasonality in Syrian hamsters (Mesocricetus auratus). Proc. R. Soc. London B265: 517-521.

Majercak J., Sidote D., Hardin P.E. \& Edery I. 1999: How a circadian clock adapts to seasonal decreases in temperature and day length. Neuron 24: 219-230.
Matsumoto A., Tomioka K. Chiba Y. \& Tanimura T. 1999: tim $^{\text {rit }}$ lengthens circadian period in a temperature-dependent manner through suppression of PERIOD protein cycling and nuclear localization. Mol. Cell. Biol. 19: 4343-4354.

Messager S., Ross A.W., Barrett P. \& Morgan P.J. 1999: Decoding photoperiodic time through Per1 and ICER gene amplitude. Proc. Natl. Acad. Sci. USA 96: 9938-9943.

Myers M.P., Wager-SMith K., Wesley C.S., Young M.W. \& Sehgal A. 1995: Positional cloning and sequence analysis of the Drosophila clock gene timeless. Science 270: 805-808.

Nuesslein-Hildesheim B., O'Brien J.A., Ebling F.J.P., MaywOOD E.S. \& HASTINGS M.H. 2000: The circadian cycle of mPER clock gene products in the suprachiasmatic nucleus of the Siberian hamster encodes both daily and seasonal time. Eur. J. Neurosci. 12: 2856-2864.

Ousley A., Zafarullah K., Chen Y., Emerson M., Hickman L. \& SEHGAL A. 1998: Conserved regions of the timeless (tim) clock gene in Drosophila analysed through phylogenetic and functional studies. Genetics 148: 815-825.

RIIHIMAA A.J. 1996: Genetic variation in diapause, coldhardiness and pupal eclosion rhythm in Chymomyza costata. Acta Univ. Ouluensis A274: 1-60.

RIIHIMAA A.J. \& KIMURA M.T. 1988: A mutant strain of Chymomyza costata (Diptera: Drosophilidae) insensitive to diapauseinducing action of photoperiod. Physiol. Entomol. 13: 441-445.

RimimaA A.J. \& Kimura M.T. 1989: Genetics of the photoperiodic larval diapause in Chymomyza costata (Diptera; Drosophilidae). Hereditas 110: 193-200.

Rothenfluti A., Abodeeley M., Price J.L. \& Young M.W. 2000: Isolation and analysis of six timeless alleles that cause shortor long-period circadian rhythms in Drosophila. Genetics 156: 665-675.

Roenneberg T. \& Merrow M. 2001: Seasonality and photoperiodism in Fungi. J. Biol. Rhythms 16: 403-414.

RuBin G.M. \& SPRADLING A.C. 1982: Genetic transformation of Drosophila with transposable element vectors. Science 218: 348-353.

Rutula J.E., Zeng H., Le M., Curtin K.D., Hall J.C. \& Rosbash M. 1996: The tim ${ }^{\text {SL }}$ mutant of the Drosophila rhythm gene timeless manifests allele-specific interactions with period gene mutants. Neuron 17: 921-929.

Rutila J.E., Suri V., Le M., So W.V., Rosbash M. \& Hall J.C. 1998: CYCLE is a second bHLH-PAS clock protein essential for circadian rhythmicity and transcription of Drosophila period and timeless. Cell 93: 805-814.

Samach A. \& Coupland G. 2000: Time measurement and the control of flowering in plants. BioEssays 22: 38-47.

Sambrook J., Fritsch E.F. \& Mandatis T. 1989: Molecular Cloning, A Laboratory Mamual. 2nd ed., Cold Spring Harbor Laboratory Press, New York.

SAUNDERS D.S. 2002: Insect Clocks. 3rd ed., Elsevier Science, Amsterdam, $576 \mathrm{pp}$.

SAunders D.S., Henrich V.C. \& Gilbert L.I. 1989: Induction of diapause in Drosophila melanogaster: Photoperiodic regulation and the impact of arrhythmic clock mutations on time measurement. Proc. Natl. Acad. Sci. USA 86: 3748-3752.

Sehgal A., Price J.L., Man B. \& Young M.W. 1994: Loss of circadian behavioral rhythms and per RNA oscillations in the Drosophila mutant timeless. Science 263: 1603-1606.

SmmadA K. 1999: Genetic linkage analysis of photoperiodic clock genes in Chymomyza costata (Diptera: Drosophilidae). Entomol. Sci. 2: 575-578.

Sumová A., Sláder M., Jác M. \& Illnerová H. 2002: The circadian rhythm of Perl gene product in the rat suprachiasmatic 
nucleus and its modulation by seasonal changes in daylength. Brain Res. 947: 260-270.

Suzuki L. \& Johnson C.H. 2001: Algae know the time of day: circadian and photoperiodic programs. J. Phycol. 37: 933-942.

TAuber E. \& Kyruacou B.P. 2001: Insect photoperiodism and circadian clocks: models and mechanisms. J. Biol. Rhythms 16: $381-390$.
Veerman A. 2001: Photoperiodic time measurement in insects and mites: a critical evaluation of the oscillator-clock hypothesis. J. Insect Physiol. 47: 1097-1109.

WEHR T.A. 2001: Photoperiodism in humans and other primates: evidence and implications. J. Biol. Rhythms 16: 348-364.

Yoshida T. \& KimuRa M.T. 1995: The photoperiodic clock in Chymomyza costata. J. Insect Physiol. 41: 217-222.

Received September 30, 2002; revised November 22, 2002; accepted December 18, 2002 